\title{
Barriers to Utilisation of Sexual Health Services by Female Sex Workers in Nepal
}

\author{
Laxmi Ghimire (Corresponding Author) \\ Department of public Health, School of Medicine \\ University of Aberdeen, AB25 2ZD, Scotland, UK \\ Tel: 44-122-455-5179Ｅ-mail: 1.ghimire@abdn.ac.uk \\ Edwin van Teijlingen \\ Department of Public Health, School of Medicine \\ University of Aberdeen, AB25 2ZD, Scotland, UK \\ Tel: 44-122-455-2491_E-mail: van.teijlingen@abdn.ac.uk
}

\begin{abstract}
Sexual health services are relatively rare in Nepal. Female sex workers (FSWs) do not use health services as often as would be desirable. A study was conducted to identify the barriers of access to sexual health services by FSWs in Nepal. A mixed-method approach consisting of a 425 questionnaire-based survey and 15 in-depth interviews was conducted in 2007.

One fifth of the FSWs had never visited health facilities. FSWs turned to private clinics, followed by clinics belonging to non-governmental organisations and pharmacies for treatment. A combination of personal and service-related factors acted as critical barriers in accessing health services. Lack of confidentiality, discrimination and negative attitudes held by health care providers, poor communication between service providers and fear of exposure to the public as a sex worker were the major barriers in seeking sexual health services. These barriers should be taken into account while planning for sexual health services.
\end{abstract}

Keywords: Service usage, Prostitution, Stigma, Women, Nepal

\section{Introduction}

Nepal is one of the least developed countries. There are many marginalised people in both rural to urban areas and the country experiences considerable seasonal labour migration (Puri \& Cleland 2006), mostly to India (MOH, 2002). Labour migrants seeking work in India constitute one of the "bridging populations" in the transmission of sexually transmitted infections (STI's) and the human immunodeficiency virus (HIV) (Sharma 2003).

Generally, Nepal has a low HIV prevalence among its adult population (below 0.5\%), but it is higher amongst Female Sex Workers (FSWs), whose national prevalence rate is 4\% (The World Bank 2007). Around the capital, in Kathmandu valley, HIV prevalence in FSWs is reported to be $17 \%$ according to the National Centre for AIDS and STD Control ( SCATS, 2001;NCASC, 2004).

The first case of HIV was reported in Nepal in 1988 and in two decades nearly 70,000 people have become infected (UNAID 2008). This increase is attributable to an active sex trade, an increasing number of injecting drug users and substantial male labour migration (FHI, 2004). Government records show that young people (aged 14-19) comprise one-sixth (13\%) of all known HIV-infected cases. Teenage girls represent about one-third of all women living with HIV (NSASC/MOH 2004). It is estimated that (UNDP, 2007), in the absence of effective public health interventions in Nepal, AIDS could become the leading cause of death among the 15 - 49 age group over the coming decade.

FSWs have limited access to appropriate information and sexual and reproductive health services. They are a highly marginalised subgroup (Day \& Ward 1997) and their social stigma is a barrier for the use of health care and treatment (Faugier et al. 1992; Romans 2001). Health services are generally not accessible to underprivileged women (Wolffers 
1999), and sexual health service usage is generally low. Rather than using a victim-blaming approach, i.e. blaming FSWs for not using routine health services appropriately, we addressed questions such as: What is the nature of FSWs' health service contact? And what are their barriers to accessing health care? This information is needed if use of current services by FSWs is to be improved (USAID 2004).

Health policy makers should reinforce the need to overcome the substantial barriers to access that exist for the poorest (Sachs 2001). The focus of much health policy intervention has been on reducing structural or services provider barriers.

\section{Methods}

\subsection{Study sample and methods}

Our study focused on FSWs aged 15-45 years who had been involved in the sex trade; in exchanging sex for money or equivalent, for at least six months prior to the survey. We combined a mixed-methods approach in two phases; a questionnaire study followed by in-depth interviews. Phase I purposively selected FSWs from a range of castes, ethnic backgrounds, work settings and exposure levels for a semi-structured questionnaire survey. In the second phase a sub-sample of volunteers from the first phase were invited for a further in-depth interview.

FSWs constitute a hard-to-reach population (Vandepitte 2006). We employed a snowball-sampling technique based on a convenience sampling method (Kruse et al. 2003). The samples was purposively identified through frontline organizations and community key informants; from international NGOs and local key informants working on issues related to sex workers and who were familiar with sex workers' activities.

Mix-method or multi-method research holds the potential for rigorous and methodologically sound studies in public health (Tashakkori 1998). The two main approaches used in this study were: (a) a semi-structured questionnaire and (b) in-depth face-to-face interviews.

An instrument was developed through the modification of questionnaires used by the World Health Organization (Cleland et al. n.d.) and FHI/Nepal (WHO 2000). The questionnaire was firstly developed in English and then translated into Nepali language. As existing instruments were modified, conducting a pilot study was important (van Teijlingen \& Hundley, 2005). The questionnaire was piloted in areas similar to the study area in other parts of Nepal to avoid contamination. Necessary modifications were made in consultation with Nepalese research experts. For the qualitative information, 15 life histories were conducted. . This sample size reflects the point where the information collected reached theoretical saturation (Barcellos Fontanella \& Turato 2005). Respondents who were working as sex workers in different settings with high-risk behaviours or experienced signs and symptoms of STIs in the survey were purposively selected. Efforts were made to select a diverse range of respondents in terms of age, marital status, ethnicity, and socioeconomic status to obtain a wide range of opinions and experiences.

A topic guideline was prepared to collect missing information from the quantitative survey. The guidelines included the main topics to be discussed, core questions, and some probing questions. This was firstly developed in English and translated into Nepali. Topics covered included knowledge and use of condoms, sexual activities and protective behaviour, potential partners, sexual harassment, characteristic of paying and non-paying partners, risk of sexual behaviour and reason for utilization and non-utilisation of sexual and reproductive health services. Interviewing is appropriate in situations where sensitive issues are addressed (Mason 2006). Conducting semi-structured interviews allowed the researcher to hold some element of control over the line of questioning (van Teijlingen \& Forrest 2004: 171), whilst still leaving scope for respondents to cover issues not directly addressed in the interview schedule.

Eight interviewers (six female and two male) were trained to conduct the phase I interviews. All were university graduates with health, sociology and/or education degrees who were experienced in conducting research on sensitive topics, and were similar to the respondents in terms of culture and age. Interviews were conducted at a convenient location chosen by the respondent, usually in a public area due to fear of disclosure of their occupation. Questionnaire completion took between 45 minutes to two hours. The in-depth interviews completed by the first author lasted between two to five hours and several visits were made to complete one case history due to emotional expression and harassment of sex workers by the police.

\subsection{Ethical considerations}

Ethical approval was obtained from the Nepal Health Research Council (ERB). Participants' full verbal and written informed consent was obtained (van Teijlingen \& Cheyne 2004) using consent forms written in Nepali and expressed in simple terms. It described the objectives, nature of the participant's involvement, risks and benefits and confidentiality of data. Participants could participate immediately or defer the interview until a later date. It was also made clear that they could refuse to answer any question and terminate the interview at any time. Those respondents who requested additional information were referred to the nearest health institutions. Confidentiality of information was maintained by removing personal identifiers, names of hotels and massage centres where FSWs operate. 


\subsection{Data processing and analysis}

All completed questionnaires were entered into a SPSS (version 15) database. Open-ended questions were coded separately. Data entry and validity checks were performed for all questionnaires. Qualitative data was analyzed using NVivo version 7 and by reading and re-reading the transcripts

\section{Results}

\subsection{Characteristics of the FSWS}

We surveyed 425 FSWs by using semi-structured questionnaire from three cities in Kathmandu Valley. Half of the respondents were street-based sex workers (50.3\%), while the remainder (49.7\%) worked within establishments such as cabins and restaurants, massage centre and hotels. In addition, we conducted 15 in-depth interviews with FSWs, four with street-based FSWs and 11 with establishment-based FSWs. Of the 15 interviewees, four were single. The age of the FSWs varied from 19 to 35 years. Four FSWs were illiterate, nine of them could simply read and write only, and two of them had studied for 10 years.

(Table 1)

\subsection{Living arrangement}

Nearly two third of the FSWs (62.6\%) had been living in their current residence for two to five years. One out of ten FSWs had stayed in their current place for six to ten years, whilst one in 20 FSWs had lived there for less than a year. Table 2 shows that more than half of the FSWs lived with a partner or husband and whether or not they had any children:

(Table 2)

\subsection{Sex work involvement}

(Table 3)

\subsection{Health service seeking behaviours and barriers}

(Table 4)

\subsubsection{Stigma and discrimination}

Powerlessness and poverty of FSWs were frequently reported as the reasons behind their low use of health services. The FSWs mentioned discrimination and stigma attached to commercial sex work. One 24-year-old FSW highlighted the double standards in Nepalese society: "many men enjoy our services but hate to us when they go out in the society."

Almost all FSWs had experienced stigma and discrimination from family, from the community and at health facilities, an example of the latter included:

Doctors should not discriminate in our treatment because of our status as some prestigious clients also visit us for our services (i.e. sex) but they have high status in the society and nobody blames them. We have no good status and we are discriminated always (FSW 2, 19 years)

FSWs reported that stigma and discrimination were barriers that may prevent them from seeking treatment for STIs and HIV from the health institutions. Most FSWs reported that health service providers in private clinics as well as doctors in the government hospital ask personal questions, particularly about their work and sexual history. This was one de-motivating factor in the pursuit of services from health facilities.

The doctor asked me about my work, when and how I got the disease? When I told him this, he looked at me differently. (FSW 2, 19 years, single)

Similarly, another FSW had visited one of the better-known hospitals in Kathmandu for treatment did not like it:

They (the Health Care Providers) ask very personal questions about me, which I do not like to answer. I am afraid of being exposed as sex worker. (FSW 3, 24 years)

An older FSW who works in restaurant spoke in a similar way:

I work in restaurant where I serve many clients. I think at least one person is enough to recognise me as sex worker while I am waiting in the queue in XX hospital. (FSW 4, 39 years)

Another FSW described her fear of recognition:

Health workers judge and recognise us as a sex worker. They might tell this to my friends and neighbours; it will be bad for me and my future life. (FSW 9, 30 years, street-based)

FSWs also reported indifference by the doctors and other health services providers as a reason for the non-use of government health services. As one FSW remarked about staff: 
They are not friendly to me. They even did not listen to my problems at first. When I told them my problems they started writing down the names of medicines without doing a proper examination. Once they knew nature of my work, they scolded me in front of other people. They act like God; no one talks about what they are doing. Are they (the doctors and nurses) God? (FSW 8, 25 years).

While one FSW specifically mentioned that Health Care workers try to charge more as they assume that FSWs have money:

We are not very comfortable with the health workers because they charge more money if they recognise us as sex workers (FSW 7, 42 years)

\subsubsection{Male doctors and feelings of embarrassment}

Three participants felt that they could not consult with male staff about their sexual health problems. They preferred female doctors in the examination room. Some FSWs were uncomfortable with discussing their genital parts with male staff, for example:

I won't tell all my problems to male doctor as I am a sex worker and ....sore in private areas...I fear scolding by doctor, ... when I was visiting XX clinic with an ulcer in the vulva, I did not ask him for an examination and ... he did not ask me my problems either, ... if female doctor was available I could have shared more with her... (FSW 11, 30 years)

Another FSW commented that the examination of her genitalia by male doctors was a reason for not visiting the hospital:

A male doctor asked me to show my private organ (Vagina) but I could not show it to him. How could I do this in such a place? So I would not like to go there again. (FSW 4, 39 years).

\subsubsection{Harassment}

Some FSWs recollected their experiences of sexual harassment by a male doctor:

The doctor asked me many questions and looked at me differently. He asked me to lie down on the examination table in a room. I did as he said. He caught my hand and pressed my body. I was scared and called my mum, who was waiting for me outside. Then I left the hospital without a check up. I do not want to go there again. (FSW 3, 34 years)

FSWs wanted harassment by police and others to stop and wished to change societal perceptions and attitudes towards sex workers. FSWs had divided opinions regarding the legalization of commercial sex. More than half of the FSWs thought that sex work needed to be legalised while the rest were in favour of working secretly, not because of their interest but because of the societal stigma attached to sex work in Nepal One FSW, who was a member of an activist women organisation, expressed her view in this way:

Sex work should be legalised, this job is very demanding of a person. Is it only the women who are to blame? I am involved in this profession and am a member of a women's right group. So, I am fighting for other women; to improve their rights and economic conditions and to secure their own and their children's futures. It takes time but one day they will realize this and legalize sex work (FSW 12, 24 years).

\subsubsection{Exploitation}

FSWs also criticized the private clinics as they charged them higher fees than they normally charge for services, as one person explained:

We are not very comfortable with the health workers because they charge more money if they recognise us as sex workers. (FSW 7, 42 years)

The younger and better-educated FSWs were in favour of the legalisation of sex work as this would result in greater provisions of Governmental security and increased economic opportunities.

One older FSW was mostly concerned about her social status. She highlighted that the agency from which FSW's would normally seek help from exploited them. She then stated that the Police also exploit them:

We need security from the Police. The Police do not provide security, but are stealing our money and threatening us. I had to give part of my earnings to the Police ... (FSW 7, 42 years)

Another FSW expressed this more generally:

We need security without any discrimination. We should be treated as human beings and treated like ordinary women in society (FSW 3, 24 years).

\subsubsection{Fear of recognition}

It was common among FSWs to seek health care treatment from distant health facilities and unfamiliar providers because of fear of recognition and subsequent stigma, for example: 
As we need to tell all our problems and nature of work to the doctor, they will certainly know us. In this situation consulting a Doctor in the nearby location is not an alternative for us. It is better to go far away so that no one, neither the Doctor nor the patients, have chance to see and recognise us again. (FSW 13, 22 years).

Several FSWs had used self-medication, because of the stigma associated within the sex work, for example, some went directly to the community pharmacist:

Getting treatment for our problems is very difficult. Many of us do not go for treatment, even if we are in need of it. We resort to going to the pharmacy to ask for medicines. Shopkeepers hand out medicine easily. (FSW 4, 39 years)

I am worried on how to tell him (doctor) these problems (STI) ? If he asks me about my work, what will I answer to him? How would I show him my face next time?' (FSW 15, 30 years)

\subsubsection{Lack of privacy and confidentiality}

According to the FSWs there was a lack of trained staff for consultation on STI's and treatment of marginalised people like sex workers. As they reported, health care staff did not appear to be fully confident in dealing with FSWs and there was a shortage of drugs for the treatment of STIs in the hospitals and clinics. Similarly, the FSW also reported that blood testing facilities within the health institutions were lacking:

I went to a famous hospital for my health check up but doctor was in a hurry and behaved in an aggressive manner while taking my sexual health history. He asked to me to visit his private clinic for a blood test. So, how could I know whether he could take blood safely in his clinic? ...I am not sure either he has proper blood instrument in his clinic! (FSW 4, 39 years)

Another FSW described her feelings about lack of confidentiality on part of the Doctors as follows:

I don't like to tell them all my personal details .....and I don't trust that they (the staff and local people) maintain confidentiality...my neighbour asked me about my work after my visit to the health institution ...she knew about my work... she overheard while the Doctor was taking my history ... So I moved from that place.' (FSW 3, 24 years)

One of the FSW commented on hospital rules and regulation in following way:

In the hospital there are many people queuing up for the treatment. I fear that someone could recognise me easily. My client also could be in attendance.... (FSW 1, 28 years)

\subsection{FSW's satisfaction with health services and providers}

Only three out of fifteen FSWs - one who had her consultation in a private clinic and two who visited hospital - were satisfied. The reason for perceived satisfaction of treatment at the private clinic was that the Doctor listened to the FSW's problem and called her for a follow up visit. But interestingly, the same FSW subsequently went to another clinic because she did not want to be recognised by the doctor. Another 30-year-old FSW who frequently suffered from STIs expressed satisfaction because she was cured from it. Few FSWs expressed neutral responses to the services they received during their last visit. One of the three FSWs was asked to attend for a follow-up visit, but the course of medicine she was prescribed was not explained to her. Another FSW was happy with the Doctor but did not feel comfortable sharing her problems and private history. Another FSW, who used to go for a routine HIV/STI test every trimester reported that she was given advice and a date for follow up visit. However, she was equally unhappy about informing the doctor about her personal history. She reported:

I can't say whether I am satisfied or not. I could not tell them my real condition. I said that I had suspicions about my husband having had sexual relationships with other women and as I result, I felt I had to undergo HIV test. I did not feel comfortable to let them know what work I do. (FSW 3, 24 years).

Many FSWs ultimately expressed their dissatisfaction of the health care services. One of the main reasons for this dissatisfaction that was mentioned was that Doctors and/or nurses, particularly from government hospitals, asked them personal questions relating to their sexual history. This is reflected in the following response of a FSW:

The doctor asks every detail of my work in a loud voice, just like if a deaf person was talking to me. In a threatening manner he told me to stop my work. He prescribed me some medicine in a sheet of paper but did not advise me about the dose or timing of the medicine. So, I decided that I would not go back to that hospital every again. (FSW 1, 28 years)

Other FSWs were not satisfied because of the long queue in the waiting room, aggressiveness of the Doctor, higher costs of treatment and fear of being stigmatised on the basis of their work.

One FSW criticised the lack of medication for HIV. She said:

My husband had a very expensive blood test. Even if it is diagnosed, they do not give out medicine. No one will care. So it's better not to have the test. (FSW 8, 30 years) 
FSWs expressed dissatisfaction at the poor communication and judgemental behaviour of the service providers. They reported that they wanted the doctors to hear their problems in detail but were equally suspicious regarding whether or not they would maintain patient privacy and confidentiality. One FSW who had visited a government hospital said:

I had been to XX hospital for a check-up on my sore vulva. I had to queue for about three hours. Finally, I was taken to the examination room. The doctor asked about my problems and started to prescribe medicines before I had finished telling my history (problems)..... He did not examine my sore vulva, but just prescribed medicine for me to buy from elsewhere (FSW 3, 24 years).

FSWs who had visited a private clinic for medication did not like it, because of the higher cost for the services provided. They reported that they had to spend Nepalese Rs: 500-2000 (UK£5-20) for their check-up. One FSW commented:

The charge for their service (STIs check) is very high. I paid RS: 2000 to see the Doctor and to receive medication and a blood test. He asked me to visit him again after a week. How can I go there, as he will charge same amount for me again? I am sure that I will not go there again. (FSW 10, 26 years)

\section{Discussion}

Sex work means high vulnerability due to FSWs' low social status and self-esteem, lack of education and skills, poverty, family responsibility, poor health, negative societal attitudes, illegal nature and legal restrictions (Cohen et al. 2000; Wong et al. 2003). This vulnerability may result in difficulties accessing health services and treatments, a lack of safe sex practices, increased abortion rates, and low negotiation power in condom use (Mardh 1999; UNAID Geneva 2002). More specifically, in Nepal, one study has documented FSWs' low access to STI services (FPAN 2006, UNAIDS/WHO 2006), and generally women with STIs are low users of health services (Tandukar, 2003). Previous studies of FSWs were largely quantitative and no study has adopted a mixed-method approach. This study offers personal accounts from 425 FSWs and case histories of $15 \mathrm{FSWs}$ from diverse age groups, education, sex work involvement, work settings and living arrangements. Women who participated in the first phase and who were willing to participate in in-depth interviews, were later re-interviewed with a focus on specific questions and topics that were not covered in the questionnaire. Because of this methodology the results provide an understanding of how FSWs see, interpret and respond to health services, and what factors influence their decisions to choose sexual health services

Our findings suggest two broad categories of factors that influence FSWs' access and use of sexual health services. These factors, internal and external influences, seem in consonance with a previous classificatory system. The internal factors are individual problems and experiences while the external factors are related to more structural influences (Shannon et al. 2008).

Rushing et al. (2005) identified several internal barriers to service use including FSWs' poor hygiene, mental instability and fear of public exposure leading to damage of social status, shame and embarrassment. This study found similar barriers. It also found that age, education level, duration of exposure to commercial sex work, feelings of insecurity due to fears of identification, low living status and livelihood problems are internal factors (see also Ensor \& Cooper 2004), as were the ability to pay for health services. By contrast, the level of self-confidence and empowerment in younger and more educated FSWs was reflected in their negotiations with their clients and in their pursuit of sexual health services. Nevertheless, as sex work is still an illegal act, fear of recognition by the police and consequently possible harassment and/or bribery was a big concern for FSWs.

Our study also confirms certain health service related or structural barriers (Kurtz et al. 2005), including: inappropriate clinic or hospital opening times, perceived low quality of the service providers, poor communication between the client and the providers; judgemental and disrespectful attitudes of the service providers and inadequate training in sexual health provision. Most Nepalese FSWs also felt a lack of privacy and confidentiality in the government hospital because of the crowd of patients and the behaviour of the health care workers. In their opinion it made them feel further stigmatised (Nepal ICDP 1998). This attitude was also found in Cape Town, Africa (Simbayi et al. 2007). Lengthy waiting times and the interpersonal behaviour of the service providers, including sexual harassment, judgemental attitudes and poor communication, were also cited as constraints to seeking health care services. Rushing et al. (2005) also identified long distance and higher travel cost, behaviours of the service providers, lack of privacy and confidentiality, consultation with multiple and substandard service providers and difficulties in accessing and negotiating the health care system as external or structural barriers. Our study confirms Rushing et al's findings.

Previous studies were undertaken examining young people's views concluded similar findings regarding sexual health services (Mackay, 2006; Langille \& Rigby 2006; McNulty et al. 2004; Nwokolo et al. 2002 and Reid et al. 2005). Hospital rules often result in women having to queue for long periods of time, and having to disclose personal information and disease history to the doctor whilst undergoing a check-up in a place without privacy. The FSWs perceived that sexual health services in the government hospital were cheaper, but the opening hours were less appropriate. Their rating of the quality of Doctors was higher in the government hospital but they had reservations over 
the privacy and confidentiality issues. Moreover, they reported that the available services were not comprehensive to them.

Some FSWs reported harassment by Doctors during check-ups. Lack of gender compatibility between the service providers and the FSWs appeared as the next service-related barrier as most of them wanted to be examined by female doctors. They felt uncomfortable referring to their private parts with male health care staff.

The private clinics and hospitals were criticised for charging higher fees, even though the doctors and nurses were perceived as being poorly trained and less experienced, a finding similar to that found in Abidjan (Vuylsteke 2004).

Satisfaction levels towards the sexual health services were mixed. The majority were dissatisfied with the poor and/or low levels of communication with the service providers, the exhaustive history taking through questions perceived to be judgemental and too personal, especially in government hospitals. Expensive medical fees, long waiting hours and inappropriate opening hours also contributed to levels of dissatisfaction. Good quality medical advice (where staff avoided asking too many personal questions) in the private clinic and clear communication regarding follow-up visits appeared to increase FSW's satisfaction levels.

\section{Conclusion}

Several conclusions could be drawn from our study in view of current health service provision for issues pertaining to STIs and HIV/AIDS among FSWs in Nepal. Information dissemination and behaviour change interventions for FSWs should focus on strengthening knowledge of STIs. To promote health-seeking behaviour, mobilizing the resources available with the involvement of establishment owners, using peer-referral approaches could greatly increase these women's utilization of health care services.

Interventions that focus on FSWs appear to be either focused on awareness rising or full prioritisation of generalised health service delivery. Therefore a two-pronged approach comprising education and service activities focusing on strengthening the health sector's STI diagnosis and treatment capabilities for both FSWs and their clients should expedite together.

FSWs are more willing to communicate with and seek health care provision from physicians/health workers who assure privacy and confidentiality. Further investigation is needed to identify a confidentiality assurance statement that explains the legal and ethical limitations of confidentiality without decreasing FSWs' likelihood of seeking future health care for routine and non-reportable sensitive health concerns. It is high time to address common discriminatory attitudes among health workers especially towards FSWs. So, training for service providers in all types of health care institutions in different levels of health care facilities need to be provided in order to promote non-judgmental specific sexual health services and appropriate counselling skills.

Integrated health services should be made available within the entire health care system as FSWs seem reluctant to use health service follow-up care provisions due to fear of being labelled as sex workers.

It is important to link the livelihood of FSW's with their empowerment, including education and improvement of their social status. It is imperative to revisit the income generating programmes implemented by the governmental and non-governmental sectors. Also, it is equally important to collaborate with the private sectors for increasing the input for quality and access to the STI and other health care services for FSWs. Health service provision for FSWs should be viewed in relation to broader socio-political perspectives rather than perceived as a mere problem pertaining to the delivery of sexual health services. Provision of a quality service that ensures the rights of FSWs should be prioritised.

\section{Acknowledgement}

We would like to offer our sincere thanks and appreciation to all of the participants, who gave their time to tell their 'painful story'. We would also like to thank the anonymous editors for their valuable comments in bringing this paper to the final stage of publication. We acknowledge Nepal Health Research Council's support in granting us ethical approval to conduct this study. Finally we would like to thank Dr. Steve Brindle for his valuable suggestions, and for copy editing the manuscript of this article.

\section{References}

Agency for International Development. (USAID 2004). Nepal's Country Profile HIV AIDS Kathmandu.

Barcellos Fontanella, B.J. \& Turato E.R. (2005). Spontaneous harm reduction: A barrier for substance-dependent individuals seeking treatment? Rev Bras Psiquiatria, 27: 272-77.

Cleland, J. Ingham, R. Stone, N.( n.d.). Asking young people about sexual and reproductive behaviours UNDP/UNFPA/WHO/World Bank special programme of research development and research training in human reproduction. Online Available: http://www.who.int/reproductive-health/adolescent/docs/qestionnaire_intro.pdf 
Cohen, M. Deamnt, C.Barken, S. Richardson, M. Young, S.Holman, S. Anastos, K. Cohen, J and Melnick, S. (2000). Domestic violence and childhood sexual abuse in HIV-infected women and women at risk for HIV. Am J Public Health 90: 560-65.

Day, S. \& Ward, H. (1997). Sex workers and the control of sexually transmitted disease. Genitourinary Med 73:161-68.

Ensor, T. \& Cooper, S. (2004). Overcoming barriers to health service access: influencing the demand side. Health Pol Planning 192: 69-79.

Family Health International (2001). Nepal Programme Overview, FHI, Kathmandu, Nepal

Faugier, J. Hayes, C. Butterworth, C. (1992). Drug-using prostitutes, their health care needs, and their clients. Manchester: University of Manchester

Hopkin, A. Gabby, J. Neuberger, J. (1994). Role of users of health care in achieving a quality service. Qual Health Care 3: 203-9.

Kruse, N. Behets, FM.T.F. Vaovola, G. et al. (2003). Participatory mapping of sex trade and enumeration of sex workers using capture-recapture methodology in Diego-Suarez, Madagascar. Sex Transm Dis, 30:.664-70.

Kurtz, SP. Surratt, HL. Kiley, MC. Inciardi, JA. (2005). Barriers to Health and Social Services for Street-Based Sex Workers. J Health Care Poor Underserved, 16: 345-61.

Langille, DB. \& Rigby, JA. (2006). Factors associated with PAP testing in adolescents in northern Nova Scotia. Can J Public Health 97: 183-86.

Mardh, P.A., Shoubnikova, M., Champlinkas, S., Unzeitig, V. (1999). Health care of female sex workers. Eur J Contraceptive Report Health Care 4: 165-80.

Mason, J. (2006). Mixing methods in a qualitatively driven way. Qualitative Res 6: 9-25.

McKay, A. (2006). Chlamydia screening programs: a review of the literature. Part 1: Issues in the promotion of Chlamydia testing of youth by primary care physicians. Can J Human Sexuality 15: 1-15. .

McNulty, C.A., Freeman, E., Bowen, J., Shefras J, Fenton KA (2004). Barriers to opportunistic chlamydia testing in primary care. Brit J Gen Pract 54: 508-14.

Ministry of Population and Environment Nepal Country Report (2002). Presented at the Fifth Asian Pacific Population Conference in Bangkok Kathmandu, Nepal.

National Centre for AIDS and STD Control (2004). HIV councelling in Nepal. Available on www.unaids.org.np/HIV/AIDS in Nepal.

Nepal: ICPD spurs changes in policies (1998) CIRDAP development digest 74: 33.

Nwokolo, N. MC., Owan, A., Hennebry, G., Chislett 'L., Mandalia, S. (2002). Young people's views on provision of sexual health services. Sex Transm Infect 78: 342-45.

Paudel, K.C., Okumura, J. \&. Sherchand, J.B. Jimba, M., Murakami, I., Wakai, S. (2003). Mumbai disease in far western Nepal HIV infection and syphilis among male migrant-returnees and non-migrants. Trop Med Int Health 8: 933-39.

Puri, M. \& Cleland, J. (2006). Sexual behaviour and perceived risk of HIV/AIDS among young migrant factory workers in Nepal. $J$ Adolescent Health 38: 237-46.

Reid, R. J, Scholes, D., Grothaus, L., Truelove, Y., Fishman, P., McClure, J. Grafton, J., Thompson R.S. (2005). Is provider continuity associated with chlamydia screening for adolescent and young adult women? Prev Med 41: 865-72.

Romans, S.E., Potter, K., Martin, J. Horbison, P. (2001). The mental and physical health of female sex workers: A comparative study. Aus New Zealand J Psychiatry 35: 75-80.

Rushing, R., Watts, C., Rushing, S. (2005). Seeking serenity living with HIV/AIDS in rural Western Canada. J Midwifery Women's Health 50: 41-44.

Sachs, J. (2001). Macroeconomics and health: Investing in health for economic development. WHO report of the commission on macroeconomics and health.

STD/AIDS councelling and training services (SCATS) (2001). female sex workers sero- prevalence study in Kathmandu, Nepal.

Shannon, K., Rusch, M., Shoveller, J., Alexson, D., Gibson, K., Tyndall, M.W., (2008). Mapping violence and policing as an environmental-structural barrier to health service and syringe availability among substance-using women in street-level sex work. Int J Drug Pol 19:140-47.

Sharma, N. (2002). HIV/AIDS awareness for migrant communities in the rural hills of Nepal. Amsterdam, Netherlands. 
Simbayi, L.C., Kalichman, S., Strebel, A.,Cloete, A., Henda ,N., Mqueketo, A. (2007). Internalized Stigma and Discrimination and depression among men and women living with HIV/AIDS in Cape Town. S Afr J Soc Sci Med 64: 1823-31.

Tandukar, K. \& Poudel, K. (2003). Factors influencing women's health services for sexually transmitted infections in eastern Nepal. [Online] Available: www.aushealthreview.com.au/publications/articles/issues/ahr/26_1

Tashakkori, A. (1998). Mixed methodology: combining qualitative and quantitative approaches, Sage, Thousand Oaks, Calif.

Teijlingen, van E. \& Cheyne, H.L. (2004). Ethics in research. RCM Midwives J 7: 208-10.

Teijlingen, van E., \& Forrest, K. (2004). Range of qualitative research methods in family planning \& reproductive health care. J Fam Plann Reprod Health Care 30: 171-73.

The World Bank, HIV/AIDS South Asia, (2007) http://www.web.worldbank.org/WBSITE/EXTERNAL/COUNTRIES/SOUTHASIAEXT/EXAccssed: 05/06/2007...

UNAIDS, (2008) HIV/AIDS estimate [Homepage of unaids], [Online] Available: Www.unaids.org/en/CountryResponces/Countries/nepal.asp 2008/11/12

UNAID, HIV/AIDS (2008) [Online] estimate available: http://www.unaids.org/en/CountryResponses/Countries/nepal.asp. Accessed: 12/11/2008

UNDP, (2007) Nepal at a glance, http://www.youndis.org/asia transmitted disease, Genitourinary Med 73: 161-68.

UNDP, (2007). Management Support to the National Programme on HIV/AIDS - MSNP [Online] Available: http://www.undp.org.np/hiv/projects/msnp/index.php?ProgramID=41. Accessed 10/11/08

USAID Washington DC, Cohen, M., Deamnt, C., Barken, S. et al. (2000). Domestic violence and childhood sexual abuse in HIV-infected women and women at risk for HIV. Am J Public Health 90: 560-65.

Vandepitte, J., Lyerla, R., Dallabetta, G., Crabbé, F., Alary, M., Buvé, A., (2006). Estimates of the number of female sex workers in different regions of the world. Sex Transm Infect 82 (Supplement 3):iii18-iii25; doi:10.1136/sti.

Vuylsteke, B., Traore, M., Mah-Bi G, Konan, Y., Ghy, P., Diarra, J., Laga,M., (2004). Quality of sexually transmitted infections services for female sex workers in Abidjan Côte d'Ivoire. Trop Med Int Health 9: 638-43.

Wolffers, I. (1999). Appropriate health services for sex workers. Research for Sex Work 2: 1-3 [Online] Available: http://www.nswp.org/pdf/R4SW-02.PDF Accessed 7-11-08.

Wong, M.L., Lubek, I. Dy. BC., Pen, S., Chhit, M. (2003). Social and behavioural factors associated with condom use among direct sex workers in Siem Reap. Cambodia. Sex Transm Infect 79: 163-65. 
Table 1. Characteristics of FSWs who completed semi-structured questionnaire

\begin{tabular}{|c|c|c|}
\hline Age group (Year) & Number* & Percentage \\
\hline - $15-19$ & 43 & 10.1 \\
\hline - $20-24$ & 145 & 34.1 \\
\hline - $\quad 25-29$ & 124 & 29.2 \\
\hline - $\quad 30-34$ & 60 & 14.1 \\
\hline - $\quad 35$ and over & 53 & 12.5 \\
\hline Year of education completed & Number & Percentage \\
\hline - None & 275 & 64.7 \\
\hline - One or less than one year & 35 & 8.2 \\
\hline - $2-5$ years & 41 & 9.6 \\
\hline - 6-10 years & 63 & 14.8 \\
\hline - $\quad$ More than ten years & 11 & 2.6 \\
\hline Total & 425 & $100 \%$ \\
\hline
\end{tabular}

One in ten FSWs was adolescents ( $\leq 19$ years), while about two-thirds were aged between 20 and29. Just one in eight was older than 35. The median age of FSWs was 26 years. The majority was between 22 to 30, and had married aged 15 to 17 years. While those interviewed in-depth, their ages varied from 19 to 39 years; seven were married, four single and four separated.

Nearly two thirds of the FSWs were illiterate (64.7\%), 14.8\% had completed six to ten years of education and only $2.6 \%$ more than 10 years.

Table 2. Living arrangements of the FSWs

\begin{tabular}{|c|c|c|}
\hline Currently living with & Number & Percentage \\
\hline - Husband $/$ partner without children & 159 & 37.4 \\
\hline - Boyfriend with children & 54 & 12.7 \\
\hline - Family & 53 & 12.5 \\
\hline - $\quad$ Friends & 116 & 27.3 \\
\hline - Alone & 32 & 7.5 \\
\hline - Children & 7 & 1.6 \\
\hline - $\quad$ Pimps & 2 & .5 \\
\hline - No response & 2 & .5 \\
\hline Total & 425 & 100.0 \\
\hline
\end{tabular}

Above table 2 shows more than half of the FSWs lived with a partner or husband either with or without children. More than one quarter of the FSWs lived with a partner, who also had a co-wife or girlfriend. More than two-thirds (68.7\%) of the interviewed FSWs had dependants currently living with them. 
Table 3. Duration of exchanging sex by age

\begin{tabular}{|c|c|c|c|c|c|}
\hline $\begin{array}{c}\text { Duration exchanging sex for money } \\
\text { or other things }\end{array}$ & $\begin{array}{c}\leq \mathbf{1 9} \text { yrs } \\
\mathbf{N = 4 3}\end{array}$ & $\begin{array}{c}\mathbf{2 0 - 2 4} \\
\mathbf{N = 1 4 5}\end{array}$ & $\begin{array}{c}\mathbf{2 5 - 2 9} \\
\mathbf{N = 1 2 4}\end{array}$ & $\begin{array}{c}\mathbf{3 0}+\mathbf{y r s} \\
\mathbf{N = 1 1 3}\end{array}$ & $\begin{array}{c}\text { Total } \\
\mathbf{N}=\mathbf{4 2 5}\end{array}$ \\
\hline - Less than a year & - & 3.4 & - & - & 1.2 \\
- $\quad$ 1-3 years & 72.1 & 61.4 & 40.3 & 32.7 & 48.7 \\
- $4-5$ years & 18.6 & 24.8 & 33.1 & 26.5 & 27.1 \\
- 6-10 years & 9.3 & 9.0 & 25.8 & 32.7 & 20.2 \\
- More than 10 years & - & 1.4 & 0.8 & 8.0 & 2.8 \\
\hline Total & 100.0 & 100.0 & 100.0 & 100.0 & 100.0 \\
\hline
\end{tabular}

About three-quarters of the FSWs had been involved in sex work for one to five years. Nearly one-half were doing sex work for one to three years.

The proportion of FSWs who had been doing sex work for a longer time gradually declined as the age gets higher and very few $(<3 \%)$ reported doing sex work for more than 10 years. Most FSWs were in their 20s and the proportion still active in sex work gradually starts to decline age 30

Table 4. Health service consultations for STI symptoms ( $\mathrm{N}=282)$

\begin{tabular}{|c|c|c|}
\hline Treatment places & Number* & Percentage \\
\hline - Private clinic & 188 & 66.6 \\
- NGO's clinic target visiting FSWs & 160 & 56.7 \\
- Pharmacy & 66 & 23.4 \\
- Government health facility & 47 & 16.6 \\
- Did not take any medicine & 21 & 7.4 \\
- Friends or relatives & 17 & 6.0 \\
- Taken home-based treatment & 13 & 4.6 \\
- Traditional healer & 7 & 2.4 \\
\hline
\end{tabular}

* Percentage total exceeds 100 due to multiple responses

Table 4 shows the health service outlets visited by the FSWs for the treatment when they thought they had STI symptoms. On the whole, 282 out of 425 FSWs $(66.3 \%)$ had visited sexual health clinic. Out of them, two-third of the FSWs consulted private clinics followed by NGO clinics (56.7\%) and pharmacies (23.4). A much smaller proportion of FSWs $(16.6 \%)$ had turned to government facilities when they experienced STIs systems. 